\title{
BMJ Open Prevalence and severity of asthmatic symptoms in Grenadian school children: the Grenada National Asthma Survey
}

\author{
D Thongkham, ${ }^{1} \mathrm{~J} \mathrm{Tran,}{ }^{1} \mathrm{M} \mathrm{T}$ Clunes, ${ }^{2} \mathrm{~F}$ Brahim ${ }^{1}$
}

To cite: Thongkham D, Tran J, Clunes MT, et al. Prevalence and severity of asthmatic symptoms in Grenadian school children: the Grenada National Asthma Survey. BMJ Open 2015;5: e008557. doi:10.1136/ bmjopen-2015-008557

- Prepublication history and additional material is available. To view please visit the journal (http://dx.doi.org/ 10.1136/bmjopen-2015008557).

DT and JT contributed equally.

Received 21 April 2015 Revised 25 August 2015 Accepted 2 September 2015

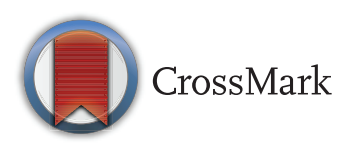

\footnotetext{
${ }^{1}$ Department of Anatomical Sciences, School of Medicine, St. George's University, Grenada, West Indies

${ }^{2}$ Department of Physiology and Neuroscience, School of Medicine, St. George's University, Grenada, West Indies
}

Correspondence to Professor MT Clunes; mclunes@sgu.edu

\section{ABSTRACT}

Objective: The goal of this study was to determine the prevalence of asthma in school children in the triisland Caribbean nation of Grenada.

Setting, participants and outcomes: This was a self-report study provided to the guardians of all primary school children between ages 6 and 7 throughout Grenada, Carriacou and Petite Martinique in 2013. Of the 2362 surveys provided, 1374 were returned, resulting in a response rate of $58.2 \%$. Only responders listing birthdays between 1 January 2006 and 31 December 2007 were included in the analysis, resulting in 1165 qualifying responders. Asthma diagnosis was based on previous physician diagnosed asthma and/or selfreported presence of wheeze in the past 12 months (current wheeze). Severity of asthma, medication usage, environmental exposures, physician and emergency department visits were compared among respondents.

Results: The prevalence of wheezing in the past year was $30.5 \pm 1.8 \%$, and of these $68.4 \%$ were previously diagnosed with asthma. Of the current wheeze participants, $39.9 \pm 9.2 \%$ reported moderate to severe asthma symptoms and increased exposure to cigarette smoke, excessive dust, burning brush and landfills. Carriacou and Petite Martinique, the two smaller islands, had a lower incidence of current wheeze $(14.1 \pm 7.7 \%)$ and exposure rates to cigarette smoke and burning brush as compared to the larger, denser island of Grenada. Although $65.7 \%$ of respondents diagnosed with asthma reported taking medication, the number of annual doctor and emergency department visits were high (2.82 and 0.86 , respectively). Respondents with the most severe asthma symptoms reported the most emergency department visits with an average of 1.05 visits annually, whereas respondents with moderate asthma symptoms had the most doctor visits with an average of 3.33 visits annually.

Conclusions: This study indicates that the prevalence of childhood asthma in Grenada is very high and warrants policy consideration in public health and education to decrease its morbidity.

\section{INTRODUCTION}

Childhood asthma is one of the most significant childhood illnesses in terms of
Strengths and limitations of this study

- First national survey of all 6-7-year olds for asthma prevalence.

- All three islands of Grenada (Grenada, Carriacou and Petite Martinique) were surveyed.

- Prevalence and severity were reported, with prevalence high for Grenada ( 30\%).

- Self-report study by parents/guardians.

- No objective measurements of airway resistance.

morbidity and mortality. ${ }^{1}$ Asthma is a chronic inflammatory disorder of the airways that is characterised by variable and recurring symptoms including airway obstruction and bronchial hyperresponsiveness. ${ }^{2}$ While there have been some studies suggesting that asthma prevalence worldwide is no longer increasing, a systematic review conducted in 2010 suggests a more complex geographical picture. ${ }^{3}$ Most notably, there seems to be an increase in asthma prevalence in developing countries. ${ }^{4}$ These findings are reiterated by surveys conducted by the International Survey of Asthma and Allergies in Childhood (ISAAC). These studies suggest that while many developed countries in North America and Western Europe have already reached their peak asthma prevalence, some developing countries of Latin America, Eastern Europe and the Caribbean continue to rise in asthma prevalence. ${ }^{5}$

Well-characterised triggers of asthma include exercise, cold air, inhaled allergens, cigarette smoke and upper respiratory viruses. ${ }^{6}$ Asthma has also been linked to environmental factors, such as exposure to tobacco smoke and dust mites, and genetic risk factors. ${ }^{4}$ Studies have demonstrated that individuals of Afro-Caribbean descent may carry a disproportionately large asthma burden. ${ }^{7}$ In a 2010 study, age matched Black Caribbean boys were reported to have higher 
rates of asthma than White and Indian girls and boys. ${ }^{8}$ Anecdotally and empirically, asthma prevalence rates are high in the Caribbean, where the vast majority of the population is of African descent.

Within the past 20 years, health officials and researchers in the Caribbean have begun tackling the emerging problem of asthma. In 1998, an asthma prevalence study conducted by Howitt et a ${ }^{\ominus}$ in Barbados concluded that over $16.8 \%$ of children aged 6-7 were diagnosed with asthma, and in 2005, Monteil et $a l^{10}$ conducted a nationwide cross-sectional survey in Trinidad and Tobago and found that $12.8 \%$ of children aged between 11 and 19 years had been diagnosed with asthma and over $24 \%$ had prior wheezing experience. Moreover, in 2010 Kahwa et $a l^{11}$ found that $16.7 \%$ of Jamaican children aged between of 2 and 17 were diagnosed as asthmatic.

To date, the Caribbean nation of Grenada, a country of $344 \mathrm{~km}^{2}$ with a population of 110152 , has not conducted an asthma prevalence study. ${ }^{12}$ Grenada is a tri-island nation made up of the large island of Grenada housing about $94 \%$ of the nation's population, and the smaller islands of Carriacou and Petite Martinique as a single parish with the remaining $6 \%$ of the population.

According to the Grenada Ministry of Health (personal communication), over the past few years the most common cause of paediatric emergency department (ED) visits at the St. George's General Hospital has been due to asthma exacerbations. The direct (hospitalisations and medications) and indirect (school/work absenteeism) costs of asthma are significant, and seem to be increasing, making it an important public health issue. ${ }^{13}$ Asthma is estimated to be among the highest costing chronic health conditions due to ED visits, hospital admissions, and medications. ${ }^{13}$ Thus, asthma is not only a significant burden on the patient and caregivers, but also on the country's healthcare system. In Grenada, the large number of paediatric hospital visits makes the pursuit of a prevalence study, effective education, and therapy important.

\section{METHODS}

Study design

Following approval by the Institutional Review Board at St. George's University, Grenada's Ministry of Education and Human Resource Development and Ministry of Health and Social Security, a nationwide cross-sectional survey of all children aged 6-7 years was conducted throughout the 58 primary schools in Grenada, from October to December 2013. This age cohort matches the previous ISAAC studies. ${ }^{5}$

\section{Data collection}

Asthma symptoms were assessed using a modified version of the phase 1 ISAAC written questionnaire with accompanying parental/guardian consent forms. The questionnaires were anonymous, although participants were asked to complete demographic characteristics such as age, gender and parish of residence. The survey questions focused on characteristic symptoms of asthma, severity of symptoms, treatment regimens, healthcare usage, family history and exposure to possible risk factors. Owing to unique environmental exposures in Grenada, one question was added to the ISAAC questionnaire about exposure to burning brush (the burning of tree and grass trimmings is common in Grenada).

A trained representative, from the non-profit organisation Urban Humanitarian Projects of St. George's University School of Medicine, visited each of the primary schools to speak about the survey to the principals, teachers and children in grades 1, 2 and 3 . Children brought a consent form and questionnaire back home to their parents to complete and return to the school for collection. Parents had an option of declining to participate in the survey by stating so on the provided forms. Of the returned surveys, those missing a date of birth or those outside the 2-year cross-sectional window of 1 January 2006 and 31 December 2007 were removed from the analysis.

\section{Data analysis}

Asthma diagnosis was based on previous physician diagnosed asthma and/or self-reported presence of wheeze in the past 12 months (current wheeze). ${ }^{5}$ The primary outcome measure of asthma prevalence was calculated and then stratified by parish to detect any disproportionally affected areas through $\chi^{2}$ tests. Secondary outcomes, including severity of symptoms (categorised as either intermittent, mild, moderate or severe as per the US National Asthma Education and Prevention Program), were also stratified by gender and analysed with a $95 \%$ CI. ${ }^{14}$

To determine if there was an association between exposure to environmental irritants and the presence/ exacerbation of asthmatic symptoms, the OR was calculated. Healthcare usage, as demonstrated by doctor visits, ED visits and number of medications taken were calculated and also stratified by severity of symptoms.

\section{RESULTS}

\section{Response rate}

Of the 2362 surveys handed out to the school children, 1374 surveys were returned, resulting in a response rate of $58.2 \%$. Females composed $53.6 \%$ of respondents and males composed the remaining $46.4 \%$. Of the returned surveys only responders listing birthdays between 1 January 2006 and 31 December 2007 were included in the data analysis, resulting in a total of 1165 qualifying responders. The number of responses collected from each parish was correlated with the reported total populations from each parish (see online supplementary table S1). The survey responses, as stratified by parish, ranged from Saint George (28.8\%) to Saint John (4.4\%).

\section{Current wheeze}

In total, $30.5 \%$ of respondents reported the presence of symptomatic wheezing over a 12-month period, that is, 
current wheeze. The parishes with the highest prevalence were St. George, St. John and St. Andrew and the lowest was Carriacou and Petite Martinique (table 1A). Moreover, while the majority of respondents with current wheeze was previously diagnosed with asthma, $31.6 \%$ reported never being diagnosed by a physician (see online supplementary table S2). Parish population density, which varies widely in Grenada, was also compared with asthma rates as densities ranged from St. George (590 persons $/ \mathrm{km}^{2}, 33.7 \%$ ) to Carriacou and Petite Martinique (179 persons $/ \mathrm{km}^{2}, 14.1 \%$ ) (see online supplementary figure $\mathrm{S} 1$ ).

Survey respondents who reported past diagnosis of asthma were on average diagnosed at $2.07 \quad(\mathrm{SE}=0.099)$ years of age (figure 1A). Current wheeze respondents were significantly more likely to have family members with asthma (figure 1B). Grenadian boys $(34.4 \%)$ were slightly more likely to report symptomatic wheezing than girls (27.7\%) (figure 1C).

\section{Gender differences}

Despite the difference in symptomatic wheezing between boys and girls, there was no significant difference in asthma severity between the sexes (table 2A). Males reported experiencing a higher frequency (ie, either daily or continuous) of cough, wheeze and shortness of breath when compared to their female counterparts (table 2B). However, there were no significant differences between the sexes when comparing exercise tolerance and school absences (table 2C, D).

\section{Exposure to irritants}

Comparing the exposure of current wheeze and no wheeze respondents to known irritants, it was found that current wheeze respondents were more likely to be exposed to cigarette smoke $(\mathrm{OR}=1.80)$, excessive dust $(\mathrm{OR}=2.90)$, burning brush $(\mathrm{OR}=2.27)$ and landfills $(\mathrm{OR}=2.46)$ (table $3 \mathrm{~A})$. When comparing the exposure of respondents from the smaller islands of Carriacou and Petite Martinique with those from Grenada, residents of the former islands were found to have significantly decreased exposure to cigarette smoke $(\mathrm{OR}=0.41)$ and burning brush $(\mathrm{OR}=0.45)$ (table $3 \mathrm{~B})$. Table $3 \mathrm{C}$ indicates that exacerbation of asthmatic symptoms occurs when current wheeze respondents were exposed to known irritants including cigarette smoke, excessive dust, burning brush, pets at home and landfills.

\section{Healthcare usage}

Of the respondents, 230 reported doctor visits for asthma, with the majority reporting 1-2 visits annually with an average of 2.82 (95\% CI of 2.42 to 3.22) (figure 2A). Respondents reported a total of $151 \mathrm{ED}$ visits for asthma exacerbations with the majority reporting 1 visit in the past 12 months and eight individuals reporting more than $5 \mathrm{ED}$ visits. The total range spanned from 0 to 12 (figure $2 \mathrm{~B}$ ). When the severity of asthma symptoms was compared to the number of doctor and ED visits, it was noted that individuals who listed their symptoms as severe had fewer doctor and more ED visits than individuals who reported moderate asthmatic symptoms (figure 2C).

Of the 225 responders who reported about asthma medication, $34.4 \%$ reported the use of no medication, $18.1 \%$ reported the use of one, $32.6 \%$ reported the use of two, and $15.0 \%$ reported the use of three or more medications (figure 2D). Respondents taking medication, compared to those who were not taking medication, also reported increased annual rates of doctor and ED visits (3.78 vs 1.22 and 1.04 vs 0.28 , respectively) (figure 2E). Additionally, when the number of medications a child reported taking was compared to the number of doctor and ED visits, it was found that children who reported taking three or more medications had fewer doctor and ED visits compared to children on only two medications (figure $2 \mathrm{~F}$ ).

Table 1 Asthma prevalence

\begin{tabular}{|c|c|c|c|c|c|}
\hline & Current wheeze & No wheeze & Per cent & $95 \% \mathrm{Cl}$ & p Value $\left(X^{2}\right)$ \\
\hline \multicolumn{6}{|c|}{$\begin{array}{l}\text { (A) Number of respondents, prevalence estimates (\%) and } 95 \% \mathrm{Cl} \text { for current wheeze throughout Grenada, Petite Martinique } \\
\text { and Carriacou }\end{array}$} \\
\hline Grenada & 355 & 810 & 30.5 & 27.8 to $33.1 \%$ & 0.038 \\
\hline Carriacou+Petite Martinique & 11 & 67 & 14.1 & 6.4 to $21.8 \%$ & \\
\hline Saint Andrew & 102 & 210 & 32.7 & 27.5 to $37.9 \%$ & \\
\hline Saint David & 47 & 115 & 29.0 & 22.0 to $36.0 \%$ & \\
\hline Saint George & 112 & 220 & 33.7 & 28.6 to $38.8 \%$ & \\
\hline Saint John & 17 & 34 & 33.3 & 20.4 to $46.3 \%$ & \\
\hline Saint Mark & 22 & 48 & 31.4 & 20.6 to $42.3 \%$ & \\
\hline Saint Patrick & 44 & 116 & 27.5 & 20.6 to $34.4 \%$ & \\
\hline \multicolumn{6}{|c|}{$\begin{array}{l}\text { (B) Number of respondents, prevalence estimates (\%) and } 95 \% \mathrm{Cl} \text { of current wheeze among individuals with or without prior } \\
\text { doctor diagnosed asthma throughout Grenada, Carriacou, and Petite Martinique }\end{array}$} \\
\hline \multicolumn{6}{|c|}{ Prevalence Comparison } \\
\hline Carriacou+Petite Martinique & 11 & 67 & 14.1 & 6.4 to $21.8 \%$ & 0.0011 \\
\hline Grenada & 344 & 743 & 31.6 & 28.9 to $34.4 \%$ & \\
\hline
\end{tabular}



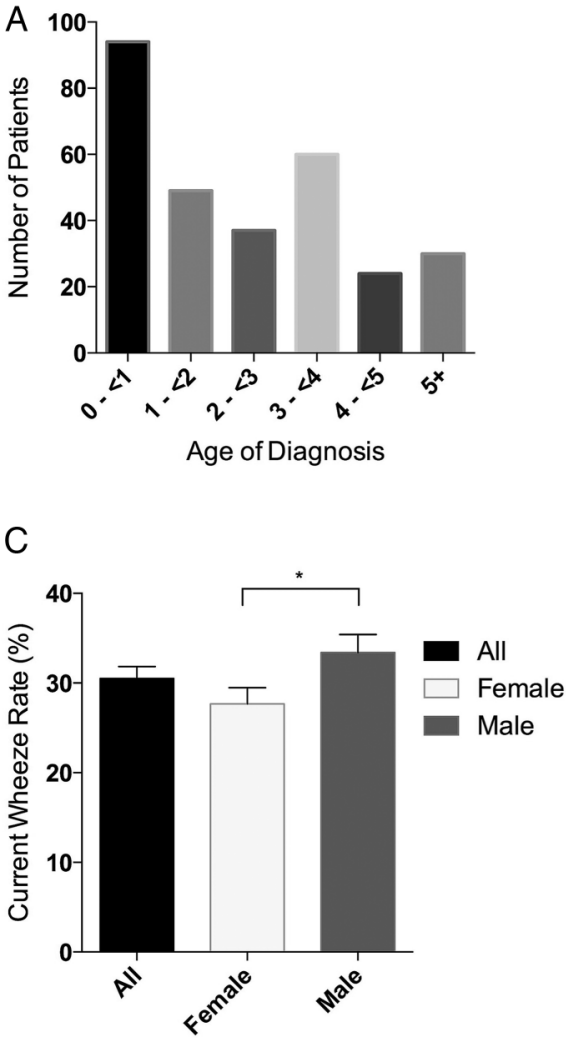

B

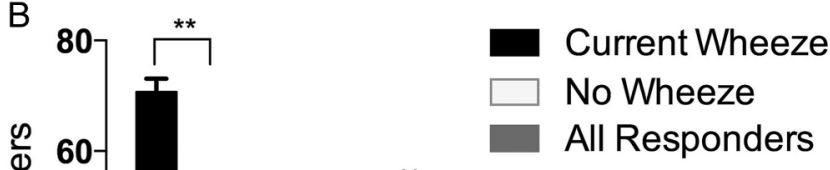

Figure 1 (A) The frequency distribution of doctor diagnosed asthma by annual age bracket, with a mean age of diagnosis of $2.07 \pm 0.19$ years. (B) the frequency distribution of current wheeze responders versus non-wheeze responders with familial history of asthma in a first or second degree relative. The frequency of current wheeze responders was significantly higher in those persons reporting any relative $(p<0.001)$, first degree relatives $(p<0.001)$ and second degree relatives $(p<0.01)$ with a history of asthma. (C) The frequency distribution of current wheeze responders by gender. The prevalence of current wheeze responders was significantly higher $(\mathrm{p}<0.05)$ in males versus females by $5.70 \%$.

\section{DISCUSSION}

The response rate from this survey was $58.2 \%$, which is comparable to previous studies performed in Trinidad with response rates of $54.0 \%$ and $73.3 \% .{ }^{10}{ }^{15}$ It was found that $30.5 \%$ of all respondents reported the presence of wheeze in the past 12 months, which places Grenada among countries with the highest prevalence of asthma including Costa Rica at $32.1 \%$ and Australia at $27.2 \%$ and significantly higher than the Global Initiative for Asthma (GINA) estimated prevalence of $10.4 \%$ in the Caribbean. ${ }^{16}$ Comparing the prevalence of asthma in Grenadian 6-7-year-olds to neighbouring Caribbean nations, Grenada demonstrates a higher asthmatic rate than Barbados at $18.3 \%$, Trinidad and Tobago at $13.3 \%$ and Jamaica at $16.7 \% .^{9-11}$ The difference between Grenada and neighbouring countries is surprising and should be explored further.

As Grenada is divided into separate parishes, part of the study was designed to determine significant regional variations. Among the six parishes that make up the largest island of Grenada, there were no significant differences in asthma rate despite known differences in healthcare resource distribution (table 1A). However, the parish of Carriacou and Petite Martinique demonstrated significantly decreased prevalence of asthmatic symptoms in comparison to Grenada (table 1B). One potential factor is that survey respondents from Carriacou and Petite Martinique reported decreased exposure to cigarette smoke and burning brush as compared to those of Grenada (table 3B). Carriacou and Petite Martinique also have significantly decreased population density (179 persons $/ \mathrm{km}^{2}$ ) as compared to the rest of Grenada (311 persons $\left./ \mathrm{km}^{2}\right) .{ }^{17}$ However, when parish population density was compared with asthma rates, there was no significant correlation between the factors, despite the large differences in population density (see online supplementary figure S1). Furthermore, studies thus far have not demonstrated a significant difference in asthma rates between dense urban areas and less-dense rural areas. ${ }^{18} 19$ These difference in asthma and irritant exposure rates between the islands warrants further research.

Estimating healthcare usage secondary to asthma was another goal for the study. Respondents with asthmatic symptoms averaged 2.88 doctor visits annually for asthma (figure 2A). In this same group, the respondents averaged $89 \mathrm{ED}$ visits per 100 respondents annually for asthma exacerbations. The rate of hospital visits is troubling when compared to developed countries like the USA whose annual rates of ED visits for asthmatic 
Table 2 Asthma severity and symptoms

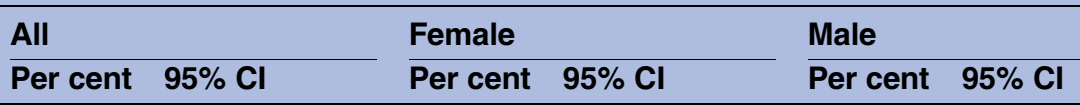

(A) The responder estimated severity of wheeze symptoms with $95 \% \mathrm{Cl}$ and gender comparison. Symptom severity is categorised as intermittent if the frequency of symptoms is less than 1 week, mild when occurring more than once a week but not daily, moderate if symptoms occur daily and persistent when symptoms are continuous

\begin{tabular}{lllllll} 
Asthma severity & $\mathrm{n}=225$ & & \multicolumn{3}{c}{$\mathrm{n}=118$} \\
Intermittent & 25.4 & $(19.8$ to $31.1 \%)$ & 28.0 & $(19.5$ to $36.5 \%)$ & 22.9 & $(15.3$ to $30.5 \%)$ \\
Mild & 34.6 & $(28.4$ to $40.8 \%)$ & 33.6 & $(24.7$ to $42.6 \%)$ & 35.6 & $(27.0$ to $44.2 \%)$ \\
Moderate & 33.8 & $(27.7$ to $39.9 \%)$ & 30.8 & $(22.1$ to $39.6 \%)$ & 36.4 & $(27.7$ to $45.1 \%)$ \\
Severe & 6.1 & $(3.0$ to $9.2 \%)$ & 7.5 & $(2.5$ to $12.5 \%)$ & 5.1 & $(1.1$ to $9.1 \%)$
\end{tabular}

(B) The frequency of wheeze, cough or shortness of breath symptoms by current wheeze responders with $95 \% \mathrm{Cl}$ and gender comparison

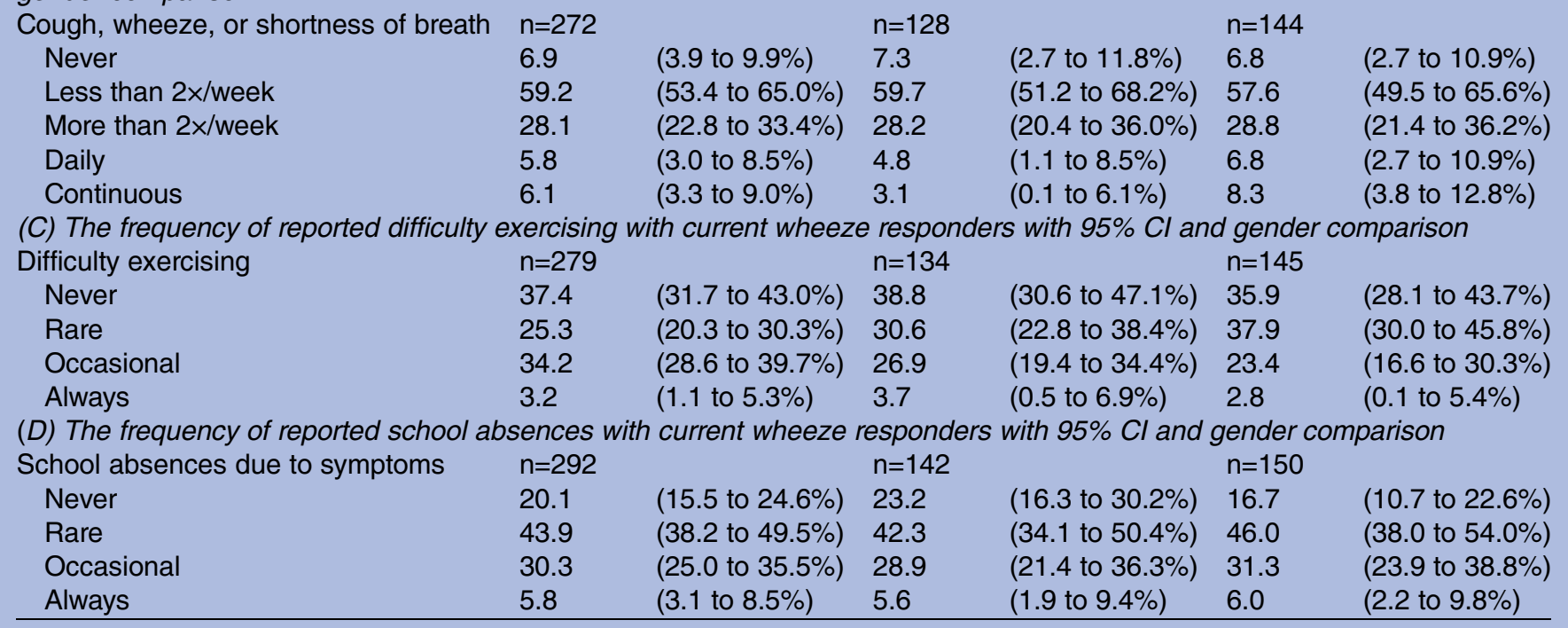

patients aged 5-14 from 2007 to 2009 was $9.5 / 100 .^{20}$ The high hospitalisation rate in Grenada raises concerns about healthcare costs, overutilisation of limited resources, and increased patient morbidity.

One potential reason for the high number of ED visits could be limited and/or sporadic access to asthma medication. Of the symptomatic respondents, $65.6 \%$ reported being prescribed prescriptions for asthma management. However, two major factors in this population that may affect asthma control are the consistent availability of medications and compliance to prescribed medical regiments. It is also noted that patients reporting the use of two medications had the highest number of doctor and ED visits, whereas patients reporting the use of three of more medications, in comparison, had a lower number of doctor and ED visits (figure $2 \mathrm{~F}$ ). This could be due to the larger number of medications controlling asthmatic symptoms more effectively or the medications could proxy for greater physician involvement and thus better primary and preventative care.

Interestingly, when comparing symptomatic patients who are medicated to those who are non-medicated, the former have increased healthcare usage in doctor and hospital ED visits (figure 2E). Furthermore, it was found that the largest users of primary care health resources such as doctor visits were respondents with moderate symptoms of asthma, while the largest users of emergency healthcare resources were individuals who reported having severe asthma symptoms (figure 2C). This could be attributed to patients with more severe symptoms being less compliant with their treatment regimens and physician check-ups compared to individuals with milder symptoms. This lack of compliance would increase the likelihood of future asthma exacerbations, which require utilisation of more expensive emergency treatments. ${ }^{13}$ Additionally, the out-of-pocket cost of healthcare, discrepancies in asthma education or medication use, and belief in traditional/ alternative forms of medicine could also be contributors to poor compliance in the Grenadian population.

An added dimension to the complexity includes patients with difficult-to-control or refractory asthma. Four respondents indicated over $10 \mathrm{ED}$ visits in the past year resulting in significant patient morbidity and hospital costs. Although these patients account for a small proportion of the total asthmatic population, these individuals typically use a large amount of healthcare resources such as physician visits, hospital admissions and medications. ${ }^{21}$

Exposure to irritants such as cigarette smoke, excessive dust, burning brush and landfills were found to be associated with asthmatic symptoms with exposure to excessive dust having the highest association (table 3A). 
Table 3 Environmental irritants

\begin{tabular}{ll}
\multicolumn{2}{c}{ Cigarette sm } \\
\hline Per cent & $95 \%$
\end{tabular}

smoke
OR
$95 \% \mathrm{C}$

\begin{tabular}{ll} 
Excessive dust \\
\hline OR \\
Per cent & $95 \% \mathrm{Cl}$ \\
& p Value
\end{tabular}

\begin{tabular}{ll} 
Burning brush \\
\hline OR \\
Per cent & $95 \% \mathrm{Cl}$
\end{tabular}

Pet

Per

$\begin{array}{ll}\text { Pets at home } \\ \text { OR } \\ \text { Per cent } & 95 \% \mathrm{Cl} \\ & \mathrm{p} \text { Value }\end{array}$

\begin{tabular}{ll} 
Landfills & \\
\hline \multirow{3}{*}{ Per cent } & OR \\
& $95 \% \mathrm{Cl}$ \\
& $\mathrm{p}$ Value
\end{tabular}

(A) The estimated frequency distribution of current wheeze and non-wheeze responders as a function of known environmental risk factors for asthma

All respondents (exposure)
Current wheeze
47.7
1.80
40.3
2.90
59.7
2.27
60.5
1.16
11.4
2.15 to $3.90 \quad 39.5$
1.74 to $2.96 \quad 56.9$
0.89 to 1.525 .0
2.46
$<0.001$
$<0.001$
$<0.001$
0.27
1.48 to 4.09
$<0.001$

(B) Comparison of the frequency

Carriacou+Petite Martinique

Grenada

20.0

0.41

0.79

27.5

0.45

51.4

0.77

4.6

0.003

0.438

0.003

0.48 to $1.24 \quad 6.8$

0.66

0.20 to 2.16 asthma

All respondents (exacerbation with exposure)

\begin{tabular}{|c|c|c|c|c|c|c|c|c|c|c|}
\hline Current wheeze & 51.6 & 7.87 & 55.5 & 10.47 & 58.7 & 7.76 & 21.8 & 5.41 & 11.8 & 9.21 \\
\hline No wheeze in 12 months & 11.9 & $\begin{aligned} & 5.74 \text { to } 10.80 \\
< & 0.001\end{aligned}$ & 10.6 & $\begin{array}{l}7.54 \text { to } 14.54 \\
<0.001\end{array}$ & 15.5 & $\begin{aligned} & 5.75 \text { to } 10.48 \\
< & 0.001\end{aligned}$ & 4.9 & $\begin{array}{l}3.50 \text { to } 8.37 \\
<0.001\end{array}$ & 1.4 & $\begin{array}{l}\quad 4.44 \text { to } 19.07 \\
<0.001\end{array}$ \\
\hline
\end{tabular}

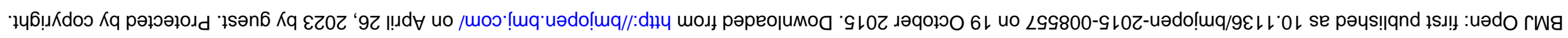


A

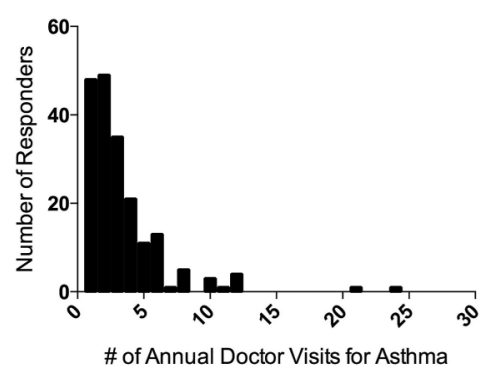

$\mathrm{D}$

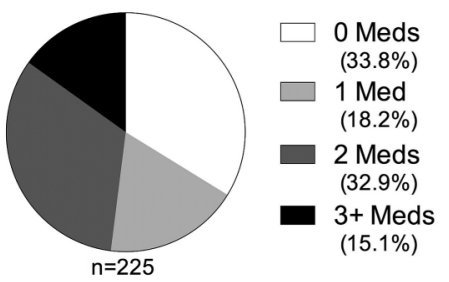

B

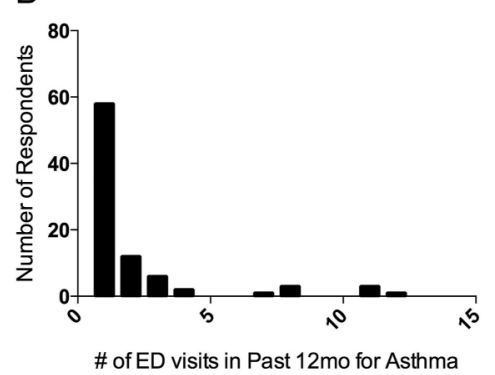

E

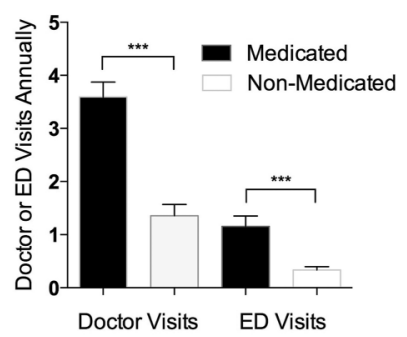

C

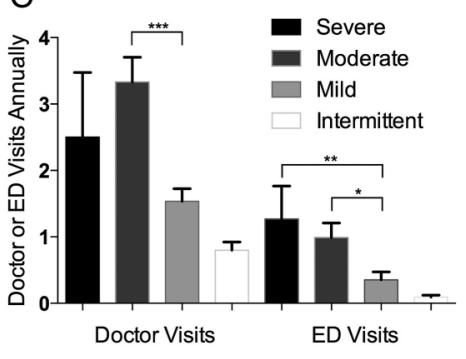

$\mathrm{F}$

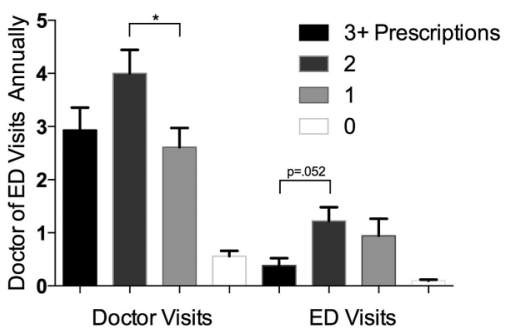

Figure 2 Healthcare burden of asthma among the current wheeze respondents for Grenada, Petitie Martinique and Carriacou. (A) the frequency distribution for the number of annual doctor visits relating to asthma. $(n=230$, total doctor visits $=649$, average annual visits $=2.82 \pm 0.40$ ) (B) the frequency distribution for the number of emergency department (ED) visits relating to asthma. $(n=213$, total ED visits $=213$, average annual hospitalisations $=0.86 \pm 0.26)(C)$ Comparison of the average number of doctor and ED visits between diagnosed asthma patients reporting different severity of asthma symptoms. (D) The fraction of doctor diagnosed asthma patients with 1, 2, 3 or more current prescriptions for control of asthma symptoms. (E) Comparison of the average number of doctor and ED visits between medicated and non-medicated patients with current diagnosis of asthma. $(F)$ Comparison of the average number of doctor and ED visits by patients with $1,2,3$ or more current asthma medications. ${ }^{*} p<0.05$, ${ }^{* *} \mathrm{p}<0.01,{ }^{* * *} \mathrm{p}<0.001$.

Because of the respondent-dependent nature of this study, it is difficult to ascertain what constitutes exposure to the aforementioned irritants. Delineating these factors could be the focus of a future study.

Despite the significant findings, because this study is self-reported, there are some limitations. First, the survey response rate of participants could be biased by therapeutic misconception, resulting in a higher survey return rate from students/families with asthma than those without. Future studies could mitigate this problem by surveying an older demographic capable of filling out the survey on site, without parental participation or engaging more directly with patients and parents. Also, as the symptoms are self-reported, they may not correlate with clinically diagnosable asthma. Thus, objective measures of asthma, including spirometry or longitudinal peak flow tracking could help corroborate future survey results. Lastly, the functional literacy of the general population in Grenada could have contributed to a non-response bias. Although Grenada has a literacy rate of $94 \%$, this does not preclude the respondents from finding the survey difficult to answer and choosing instead not to participate in the survey. ${ }^{17}$ Test trials of questions to sample populations could be used in future studies to ensure proper comprehension of survey questions and minimise non-response bias from poor understanding.
Asthma remains a significant health issue in Grenada and other Caribbean nations; it causes substantial patient morbidity, stresses financial resources, and decreases productivity through school absences. The treatment of asthma, particularly asthma exacerbations, utilises significant amounts of medical and hospital resources, which can strain any healthcare system. This survey represents the first attempt at gathering cross-sectional data for the prevalence of asthma in Grenadian children and uncovers some surprising findings. Of note, the higher prevalence rate of asthma in Grenada (30.5\%) compared to neighbouring Caribbean nations and the relatively decreased prevalence of asthma in Carriacou and Petite Martinique compared to Grenada. The results of this study provide important data about the burden of asthma on the patient and on the nation's healthcare expenditure. These findings lay the framework for understanding the asthma epidemic in Grenada. Future studies in Grenada should focus on identifying the modifiable, environmental drivers of asthma and creating cost-effective healthcare interventions that decrease emergency treatments and patient morbidity.

Acknowledgements The authors would like to thank Cecilia Hegamin Younger, PhD, MPH; Vishnu Rao, PhD; Fred M Jacobs, MD, JD; Vijaya Chellapilla, MD; and Trevor Noel MPH for their support and guidance with this project. The authors would also like to thank survey collection and data entry volunteers: Natalie Bergstrom, Amber Chess, Samfee Doe, Kristen Graetz, Ryan Golden, Mira Uphadya, Marie Maniscalco, Melissa Jackson, Jade 
King, Seye Olafimihan, Ashkon Banihashemia, Bekah Banihashemi, Daniel Good, Brittany Good, Michael Smith and Rebecca Thongkham.

Contributors DT and JT were responsible for planning, conducting, analysing and reporting this study. MTC was responsible for the data analysis and reporting of this study. FB was responsible for the planning, data analysis and reporting of this study.

Funding This work was funded by Urban Humanitarian Projects, the charitable arm of the medical student honor society (Iota Epsilon Alpha) at St. George's University, with support from St. George's University, Grenada's Ministry of Education and Human Resource Development, and Ministry of Health and Social Security.

Competing interests None declared.

Ethics approval St Georges University IRB.

Provenance and peer review Not commissioned; externally peer reviewed.

Data sharing statement Additional data can be accessed via the Dryad data repository at http://datadryad.org/ with the doi:10.5061/dryad.q68m1.

Open Access This is an Open Access article distributed in accordance with the Creative Commons Attribution Non Commercial (CC BY-NC 4.0) license, which permits others to distribute, remix, adapt, build upon this work noncommercially, and license their derivative works on different terms, provided the original work is properly cited and the use is non-commercial. See: http:// creativecommons.org/licenses/by-nc/4.0/

\section{REFERENCES}

1. Masoli M, Fabian D, Holt S, et al. The global burden of asthma: executive summary of the GINA Disseminiation Committee report. Allergy 2004;59:469-78.

2. National Asthma Education and Prevention Program. Expert pane report III: guidelines for the diagnosis and management of asthma. Bethseda, MD: National Heart, Lung, and Blood Institute, 2007. (NIH Publication no. 08-4051) http://www.nhlbi.nih.gov/guidelines/asthma/ asthgdln.html (accessed on 17 Feb 2015)

3. Anandan $\mathrm{C}$, Nurmatov $\mathrm{U}$, van Schaych OCP, et al. Is the prevalence of asthma declining? Systemic review of epidemiological studies. Allergy 2010;65:152-67.

4. Eder W, Ege MJ, von Mutius E. The asthma epidemic. N Engl J Med 2006;355:2226-35.

5. Pearce N, Ait-Khaled N, Beasley N, et al. Worldwide trends in the prevalence of asthma symptoms: phase III of the International Study of Asthma and Allergies in Childhood (ISAAC). Thorax 2007;62:758-66.

6. Vernon MK, Wiklund I, Bell JA, et al. What do we know about asthma triggers? A review of the literature. J Asthma 2012;49:991-8.

7. Smyth RL. Asthma: a major pediatric health issue. Respir Res 2002;3(Suppl 1):S3-7.

8. Whitrow MJ, Harding S. Asthma in Black African, Black Caribbean and South Asian adolescents in the MRC DASH study: a cross sectional analysis. BMC Pediatr 2010;10:18.

9. Howitt ME, Roach TC, Naidu R. Prevalence of asthma and wheezing illnesses in Barbadian school children: the Barbados National Asthma \& Allergy Study [Abstract]. West Indian Med J 1998;47(Suppl 2):22-3.

10. Monteil MA, Joseph G, Changkit C, et al. Comparison of prevalence and severity of asthma among adolescents in the Caribbean islands of Trinidad and Tobago: results of a nationwide cross-sectional survey. BMC Public Health 2005;5:96.

11. Kahwa EK, Waldron NK, Younger NO, et al. Asthma and allergies in Jamaican children aged 2-17 years: a cross-sectional prevalence survey. BMJ Open 2012;2:pii: e001132.

12. The World Factbook. Grenada. 2014. https://www.cia.gov/library/ publications/the-world-factbook/geos/gj.html Last updated 20 June 2014. (accessed on 17 Feb 2015)

13. Bahadori K, Doyle-Waters MM, Marra C, et al. Economic burden of asthma: a systematic review. BMC Pul Med 2009;9:24.

14. Colice $\mathrm{G}$. Categorizing asthma severity: an overview of national guidelines. Clin Med Res 2004;2:155-63.

15. Mahabir D, Pooran SV, Motilal H, et al. Acute severe asthma in Trinidad and Tobago. Int J Tuberc Lung Dis 1999;3:198-201.

16. Global Initiative for Asthma. Global strategy for asthma management and prevention. 2015 edition. Retrieved from: http://www.ginasthma. org/local/uploads/files/GINA_Report_2015_May19.pdf (accessed 7 Jul 2015).

17. Government of Grenada. About Grenada. Last updated 7 May 2013 Retrieved from: http://www.gov.gd/about_grenada.html (accessed on 15 Jul 2015).

18. Keet CA, McCormack MC, Pollack CE, et al. Neighbourhood poverty, urban residence, race/ethnicity, and asthma: rethinking the inner-city asthma epidemic. J Allergy Clin Immunol 2015;135:655-62.

19. To T, Stanojevic S, Moores G, et al. Global asthma prevalence in adults: findings from the cross-sectional world health survey. BMC Public Health 2012;12:204.

20. Moorman JE, Akinbami LJ, Bailey CM, et al. National Surveillance of Asthma: United States, 2001-2010. National Center for Health Statistics. Vital Health Stat 3 2012;(35):1-67.

21. Wener RRL, Bel EH. Severe refractory asthma: an update. Eur Respir Rev 2013;22:227-35. 